\title{
Improving resilience of infrastructure: the case of bridges
}

\author{
James Brownjohn ${ }^{1}$ and Emin Aktan $^{2}$ \\ ${ }^{1}$ University of Sheffield Dept. of Civil and Structural Engineering, Mappin Street, \\ Sheffield S1 3JD, +44 114 2225771, james.brownjohn@sheffield.ac.uk \\ 2Drexel University aaktan@drexel.edu
}

\begin{abstract}
Three well known examples of I-35W bridge failure, London Hammersmith Flyover closure and the UK M1 motorway under-bridge fire highlight the need for a reliable decision support methodology to enable better informed decisions on timely intervention and/or resilient recovery from a damaging event. It seems that quite apart from extreme man-made or natural hazards, our transportation infrastructure is not resilient under man made or natural loads, and we need to leverage technology to better understand and respond to societal risks due to a lack of resiliency. The challenge to improve infrastructure resilience has led to major infrastructure research initiatives that are relevant to the case of bridges. FHWA created the Long Term Bridge Performance Program, while in the UK, EPSRC recently promoted the two themes of resilient infrastructure and monitoring and field investigation of existing infrastructure.

The paper will describe these initiatives and how they aim to improve the resilience of bridges, which are key components in our transport infrastructure. It will also suggest some specific activities for developing closer interactions between a wide range of academic and industry stakeholders leading to development effective decision support methodologies.
\end{abstract}

\section{INTRODUCTION: DEFINITIONS OF RESILIENCE}

Resilience is a term widely used but misunderstood and poorly defined. For example the UK Institution of Civil Engineer's 2009 'Defending Critical Infrastructure' report (Institution of Civil Engineers, 2009) uses the word 37 times without definition.

One of the most useful definitions is from the field of Earthquake Engineering which defines it as a function indicating capability to sustain a level of functionality or performance for a given asset or network over a period of time including the recovery period after damage in an extreme event. The recovery time is that needed to restore the functionality of an asset or network, allowing proper operation of the system (Cimellaro et al., 2006). This definition encapsulates the possibility of structural damage, the issue of resuming normal functionality and the important of the recovery time. 
Cabinet Office (2011) defines Infrastructure resilience as the ability of assets and networks to anticipate, absorb, adapt to and recover from disruption.

Resilience can be measured by the scale of challenge that the system can endure beyond normal demand and, in decision making, may be balanced against other competing factors by what is proportional, affordable and tolerable. Hence resilience can be regarded as the ability to maintain functionality and return to normality following a damaging event, ensuring that damage or disruption is proportionate, tolerable and affordable (Hudson et al., 2012).

According to Blockley et al. (2012), infrastructure resilience is the ability of an infrastructure system to withstand or recover quickly from difficult conditions. It is not a simple property like a safety factor or probability of failure and it is linked to vulnerability and robustness, as follows.

A system is vulnerable if it is susceptible to damage or perturbation, especially where small damage or perturbation leads or cascades to disproportionate consequences. A system is not robust if it is vulnerable and since robustness is ability of a system to persist with changing conditions, a system that is resilient is also robust. This interdependence of resilience and robustness, with robust systems being inherently more resilient, is explored in (Marjanishi \& Hinman (2010).

A central aspect of vulnerability - and hence robustness and resilience - of technical and sociotechnical systems is how to ensure that 'surprises' are managed, especially those that have high impact but are of low chance or probability. Surprises come as 'unknown unknowns', the high impact low probability events (Government Office for Science (2011) or 'black swans' (Taleb, 2007).

Performance optimisation of an infrastructure asset or system can increase its vulnerability and reduce its resilience. This phenomenon is clearly seen in slender structures such as long span floors and bridges. Surprises like London Millennium and Tacoma Narrows bridges cannot be hidden from public view and they epitomise optimisation/resilience trade-off. Resilience may be improved by overdesign but this is neither rational nor economically or environmentally viable.

\section{RESILIENCE IN BRIDGES, STRUCTURAL IDENTIFICATION AND DECISION SUPPORT}

Bridges are critical infrastructure assets. Apart from direct financial loss and fatalities, their strategic important in transport networks leads to disproportionate indirect costs. Hence a bridge which is not resilient means a network that is not. Such a lack of resilience is obvious, for example in the case of three recent UK bridge incidents.

1) The extended closure of the M1 motorway near London in 2011 due to arson demonstrated disproportionate disruption of a vital national network and the need for reliable post-trauma structural assessment using pre-trauma measured data. 
2) The 2011 closure of Hammersmith Flyover highlighted unreliable and disruptive lowtech inspection and maintenance regimes. Lack of prior structural performance track record and means to assess impact of discovered damage forced the usual conservative approach to safety yielding sudden bridge closure and transport chaos.

3) The M4 Boston Manor viaduct was closed 3 weeks before the 2012 Olympics due to discovery of a new crack in a "sensitive location" during minor repairs of a fault found earlier by chance.

The collateral damage in these cases i.e. economic loss due to traffic disruption was incalculable -which emphasises that these critical infrastructure components demand our attention. The last two cases added potential political embarrassment at a time of negative sentiment about the forthcoming London Olympic Games, and all resulted in large direct financial consequences.

A major contributing factor in each of these cases, and in fact in any bridge whose condition is rendered uncertain as a result of discovery of a major defect or natural hazard (earthquake damage or pier scour due to flooding for example) is the uncertainty about the structural condition and the impact on its safety. It was the threat of total collapse that kept the three London bridges out of service for so long, extending recovery time and compounding the impact.

Obtaining structural information still relies heavily on visual assessments and back analysis, but because this may be highly subjective, there is a very strong case for structural identification (ASCE-SEI, 2013) using direct or indirect measurements of structural loading and response. This may take the form of an intensive one-off condition assessment (medical analog: diagnostic investigations such as MRI) or extended structural monitoring (medical analog: cardiac/respiratory monitoring). These technologies are now maturing, but the issue remains of how to leverage the information from these investigations for effective decision support for rapid and economic recovery.

Structural monitoring. Dynamic monitoring is relatively common in seismic zones with strong motion programs, although their potential for post-earthquake trauma seems to be underdeveloped, with very little is reported on the use of such instrumentation for post-trauma assessment. Two examples are use of a strong motion monitoring system to check effects of ship impact on Vincent Thomas Bridge (Yun at al., 2008) and an attempt to use ambient vibration survey to assess possible earthquake damage on a 7storey Los Angeles building (Ivanovic et al., 2000). While it is hard to find published accounts of successful damage evaluation, two research exercises based on major construction events show the potential:

The first (Moyo et al, 2002) used slow-sampled strain time series to identify construction events such as post-tensioning, showing the possibility to identify deconstruction events such as tendon tension loss.

The second (Brownjohn et al., 2013) was the two-year vibration monitoring of a 19 storey university building during major retrofit in which effects of removing 'nonstructural' elements were clearly visible in dynamic behaviour. 
Structural health monitoring (SHM) technology, which is structural monitoring with added intelligence, is an innovation of the last two decades (Brownjohn, 2007) and is sometimes linked to vibration-based damage detection (Doebling et al., 1996). In that capacity some advocates (over-)sold its capabilities to detect damage and assess structural state, whereas the most successful SHM applications have been in characterising operational loading and performance and in retrofit evaluation.

Except for a few specific forms of damage e.g. involving boundary conditions (supports, bearings, expansion joints) the link between damage and performance can be rather subtle. However, dealing with such subtlety is academically attractive, so development of sophisticated data mining (pattern recognition) technologies is a promising direction for resolving what is essentially a signal/noise ratio problem.

The potential for real time structural diagnosis and decision support through SHM has been sufficient to establish business cases for a number of commercial organisations and to drive an expanding research area. However, the authors believe there is lack of focus on the real challenge, which is the development of effective decision support technologies based on monitored bridge performance data. Further, there is a risk of technology-push without proof of any real value to owners and users, eventually creating a negative impression of technology.

As well as 'permanent' monitoring systems, temporary monitoring systems e.g. for vibration monitoring (Brownjohn et al., 2011) are used for specific and well-defined purposes e.g. of assessing efficacy of retrofit, investigating environmental loadings such as excessive vibrations (due to wind or pedestrians) and assessing fatigue.

Condition assessment. In this context we refer to investigative campaigns of which modal testing (Ewins, 2000) and system identification (Hart et al., 1977) are a significant subset. There is significant literature e.g. (Salawu \& Williams, 1995) with more recent examples (Brownjohn et al., 2003; Catbas et al., 2006). The 'International Bridge' test-bed exercise (CAIT, 2011) from 2010 to 2011 showed how a range of evaluation technologies including vibration and deflection measurements could be fused with standard evaluation techniques to provide a through structural evaluation. The exercise aimed to highlight the most cost-effective technologies as a demonstration to bridge authorities considering deploying them.

Decision support. Of itself the spectrum of experiment-based activities spanning monitoring and condition assessment provides information about performance regimes and structural condition. The major research challenge facing us is how to leverage this information for decision support, and how to optimise the condition assessment and monitoring technologies to provide the most relevant and reliable information for the minimum cost.

As well as providing information for operational management and intervention, such systems will play a crucial role in resilient recovery from trauma due to natural hazard (primarily earthquake and flood), accidents (fire, impact) and partial failure due to degradation. 
Bridge management systems by themselves have not been a success story in decision support (Flaig \& Lark, 2000), and the way forward appears to be via formalised decision support systems (Freudenthaler et al., 2009). Such systems are by definition not expected to be fully automated, and realistically bridge monitoring/SHM systems can be expected to augment rather than replace the capability of the experienced bridge engineer by providing condition information (Wenzel, (2009).

The elements of such a SHM-based DSS might include: definition of performance metrics, permanent and temporary instrumentation, data management and mining, performance modelling and scenario simulation, access to bridge performance knowledge base, and case based reasoning methodologies to support decisions, all available through a user-oriented interface.

DSS approaches for bridges can benefit from approaches taken across the broader class of civil infrastructure e.g. Condition Monitoring and Asset Management (CMAM) for Complex Infrastructure Systems project (EPSRC, 1999). This maps what can be measured (loads \& responses onto high-level bridge performance requirements (e.g. asset condition and resilience) using Hierarchical Process Modelling (Marashi \& Davis, 2006; Davis \& Hall, 2003; Davis et al., 2007).

\section{ADDRESSING THE PROBLEM: DATA TO DECISION SUPPORT}

In the USA, the Federal Highway Administration (FHWA) has attempted to address the real world challenge of managing bridges with the Long Term Bridge Performance Program (FHWA, 2008), one of which aims is to develop decision support tools and methodologies. The International Bridge Study (CAIT, 2011) that brought together an international team of researchers in 2010-2011 was one part of this program.

Meanwhile, ASCE's Structural Engineering Institute brought together a different (but overlapping) team of researchers for a state of the art report on 'Structural Identification of Constructed Facilities' (ASCE-SEI, 2013). This report shows how experimental and analytical arts are fused to provide exactly the kind of information required for reliable decision support.

In the UK, the Engineering and Physical Sciences Research Council (EPSRC) funded Future Infrastructure Forum (FIF) (EPSRC, 2011) was set up to initiate dialogue amongst key UK stakeholders to address the challenge of providing and managing sustainable and resilient infrastructure. These were two of the key research challenges identified in the EPSRC's Strategic Review of Ground and Structural Engineering (GSE) (EPSRC, 2009). FIF established a consensus between a large group of stakeholders and UK structural engineering academics on the importance of monitoring for optimal management of sustainable performance of existing and new infrastructure and number of initiatives are merging from the GSE/FIF exercise.

The FIF debate emphasised the opportunity for a major integrating effort between stakeholders and researchers that will lead to a user-centred approach to design of decision support systems based on structural performance monitoring that are cost effective and provide the right information to the right people at the right time. 
Similar challenges of linking data to decisions map to other industries. The switch by aero-engine manufacturers from selling engines to selling power-hours to airlines has driven engine reliability improvements and shifted costs of maintenance and failure to a more uniform operational expenditure model. Real time monitoring of engine fleets in service around the world (Waters, 2009) enables diagnostic and prognostic assessments following an engine problem, directing immediate corrective action. With the ability to diagnose engine problems in real time and remotely, there is no need to ground aircraft fleets with the same engine. A business case for monitoring and decision support is developed by the manufacturer acquiring a shared interest with the customer in ensuring long term reliability and cost effectiveness of the engine, along with a steady income stream as a service provider (Anon, 2011). This is a perfect model of resilient behaviour and similar ideas and compelling business cases map to civil infrastructure assets.

\section{SOME SUGGESTIONS TO IMPROVING BRIDGE RESILIENCE}

We build on the problem of improving resilience to one of decision support i.e. empowering infrastructure stakeholders to make optimal decisions on structural intervention following structural trauma or the immediate threat of it.

Clearly the authors are advocates of structural identification (St-Id) as a means to support decision making, but we recognise that while the technologies even for this relatively narrow paradigm extend well beyond the comfort zone of the traditional civil/structural engineer, we have to join forces with and learn from specialists in other domains.

Research funding and collaboration. A joined up approach to developing decision support for infrastructure (and bridges in particular) requires a combined effort from the wide range of stakeholders. What has surprised the authors is the keen interest and 'pull' of the stakeholder groups to team up with academia, demonstrated in FIF and LTBP, whereas many efforts in this area have been pushed by small teams of academics driving their own agendas. This is where funders need the necessary vision to support development of such approaches. The requirement by Research Councils UK EPSRC for proposals to emphasise impact and national importance are strong encouragements to include stakeholder as partners, but presently confusing definitions of research priorities in the area of infrastructure work against it.

As these representations show, infrastructure DSS needs to extend beyond the traditional domain of the engineer to include econometrics, social sciences and informatics.

Most funding agencies are somewhat passive in their support for international collaboration and working across disciplines. Joint international proposals suffer from double jeopardy reviewing while cross-disciplinary work poses major challenges in fair and effective reviewing. This is why an initiative such as FIF does not go far enough and research funders need to pay more attention to research agenda development (Hansman et al., 2006, Aktan et al., 2012). 
Dissemination and engagement. This is really a prerequisite for developing academia/industry stakeholder research partnerships seeking funding. Meetings such as ASCE Structures Congress, IABMAS (iabmas.org), SHMII (ishmii.org), IABSE (iabse.org) and TRB (trb.org) show a good balance of both groups, and there are further opportunities for crossover with stakeholder-oriented meetings e.g. International Cable Stayed Bridge Operators Conference (icsboc.com) and the multiple academic-focussed meetings. Initiatives such as FIF (EPSRC, 2011) have provided excellent opportunities while technology demonstrators such as IBS (CAIT, 2011) are highly effective means of educating stakeholders about state of the art.

Educating engineers. We need to rethink our civil engineering curricula (Aktan \& Brownjohn, 2013) to reflect the necessary shift of emphasis from design and analysis to encompass operation and maintenance. A huge proportion of infrastructure asset lifecycle cost is in the life (and death) after construction yet this area suffers from underemphasis and an image problem.

It is not just undergraduate curricula that need changing (MEng in UK, BS in USA), it is taught postgraduate (MSc in UK) curricula where student (mainly overseas) seek vocation training to equip them for and provide access to industry, where we can provide the necessary skills, in short-course style, for infrastructure operation and maintenance modules that cover skills in structural identification and life cycle management. There are needs for both specialist courses e.g. in 'civionics' (Mufti et al., 2005) and courses covering the broader areas of infrastructure asset management.

Finally doctoral programmes need to take on board the necessary breadth of skills required for developing future leaders in the infrastructure decision support sector, both for academia and non-academic stakeholders. To this end the EPSRC-funded Centres for Doctoral Training (EPSRC, 2012) and a subset of Industrial Doctorate centres (EPSRC, 2009) by their nature require strong industry engagement and promote the type of interdisciplinary approach future PhDs will need for working in this area.

Perhaps the most important consideration is forming partnerships with infrastructure owners-operators to leverage real infrastructures as living field laboratories for training of this emerging breed of researhers.

\section{CONCLUSION}

Authors believe that bridge resilience is best managed by effective decision support methodologies and that their development requires not only a blend of nontraditional engineering skills but also engagement outside traditional engineering boundaries.

There have been several recent encouraging developments in UK and USA where academic and industry stakeholders have worked together, supported by funding agencies to develop this area, but it is still at a very early stage needing strong support and non-traditional thinking to compete for funding with big science. 
Lack of resilience in bridges brings home the importance of this area and with the current climate of promoting investment in infrastructure as a Keynesian tool, our community needs to sustain and enhance the momentum and prove (to funding agencies) the high return on investment possible through investment in research in this area.

\section{REFERENCES}

Aktan, A., Bartoli, I., Moon, F., (2012), “Cystallizing societal concerns for the built environment and the infrastructure performance problem." Open letter to National Science Foundation.

Aktan, A.E., Brownjohn, J.M.W., (2013). "Structural Identification: Opportunities and challenges." Journal of Structural Engineering.

Anon, (2011). "A tale of two industries". The Economist, June.

ASCE-SEI, (2013). "Structural Identification (St-Id) of constructed facilities." www.cece.ucf.edu/people/catbas/St ID Report (Jan 11 2011) ALL Chapters.pdf

Blockley, D.I., Godfrey, P., Argawal, J., (2012). "Infrastructure Resilience for highimpact low-chance risks". Civil Engineering, Proceedings of the Institution of Civil Engineers 165(CE6), 13-19.

Brownjohn, J.M.W., Koo, K-Y., Basagiannis, C., Alskif, A., Ngonda, A., (2013). "Vibration monitoring and condition assessment of the University of Sheffield Arts Tower during retrofit." Journal of Civil Structural Health Monitoring .

Brownjohn, J.M.W., (2007). "Structural health monitoring of civil infrastructure." Philosophical Transactions A, Royal Society 365(1851), 589-622.

Brownjohn, J.M.W., Xu, Y-L., De Stefan, A., Wenzel, H., Aktan, A.E., (2011). "Vibration-based monitoring: Success and challenges." Journal of Civil Structural Health Monitoring 1 79-95.

Brownjohn, J.M.W., Moyo, P., Omenzetter, P., Lu, Y., (2003), “Assessment of highway bridge upgrading by dynamic testing and finite element model updating." Journal of Bridge Engineering, 8(3), 162-172.

CAIT, Centre for Advanced Infrastructure \& Transportation, (2011). "International Bridge Study." cait.rutgers.edu/ibs-2011-resources

Catbas, F.N., Brown, D.L., Aktan, A.E., (2006). "Use of modal flexibility for damage detection and condition assessment: case studies and demonstrations on large structures.” Journal of Structural Engineering 132(11) 1699-1712.

Cimellaro, G.P., Reinhorn, A.M., Bruneau, M. (2006). “Quantification of Seismic Resistance." Proceedings of the $8^{\text {th }}$ US National conference on Earthquake Engineering, San Francisco, Paper 1094.

Cabinet Office, (2011). "Keeping the County Running: Natural Hazards and Infrastructure." cabinetoffice.gov.uk/resource-library/keeping-country-runningnatural-hazards-and-infrastructure

Davis JP \& Hall JW (2003). "A software-supported process for assembling evidence and handling uncertainty in decision-making." Decision Support Systems, 35(3). 
Davis et al., (2007). "Perimeta", www.bris.ac.uk/civilengineering/research/systems/projects/perimeta.html

Doebling, S. W., Farrar, C.R., Prime, M., Schevitz, D. W., (1996). "Damage identification and health monitoring of structural and mechanical systems from changes in their vibration characteristics: a review." Los Alamos National Labs Report LA-13070-MS UC-900.

EPSRC, (2011).Future Infrastructure Forum (FIF) gow.epsrc.ac.uk/NGBOViewGrant.aspx?GrantRef=EP/J004294/1

EPSRC, (2009). epsrc.ac.uk/SiteCollectionDocuments/other/2009gsereview/mainreport.pdf

EPSRC, (2012). www.epsrc.ac.uk/funding/students/centres/2013cdtexercise

EPSRC, (2009). www.epsrc.ac.uk/funding/students/centres/current/Pages/indd.aspx

EPSRC, (1999). “Condition Monitoring and Asset Management (CMAM) for Complex Infrastructure Systems"

http://gow.epsrc.ac.uk/NGBOViewGrant.aspx?GrantRef=GR/M53073/01 publications.environment-agency.gov.uk/PDF/SCHO1205BKAW-E-E.pdf

Ewins, D.J., (2000). Modal Testing: theory and practice ( $2^{\text {nd }}$ Edition). Research Studies Press.

FHWA, (2008)

http://www.fhwa.dot.gov/research/tfhrc/programs/infrastructure/structures/ltbp/

Flaig, K.D., Lark, R.J. (2000). "The development of UK bridge management systems." Transport, Civil Engineering, Proceedings of the Institution of Civil Engineers. 141(2), 99-106.

Freudenthaler, B., Kung, J., Gutenbrunner, G., (2009). "Case-based decision support for the assessment of bridges." International Journal On Advances in Intelligent Systems, 2(1), 226-240.

Government Office for Science, (2011). "Blackett Review of High Impact Low Probability Events." bis.gov.uk/assets/goscience/docs/b/12-519-blackett-reviewhigh-impact-low-probability-risks

Hansman, R.J., Magee, C., de Neufville, R., Robins, R., Roos, D., (2006), "Research agenda for an integrated approach to infrastructure planning, design and management." International Journal of Critical Infrastructures 2(2/3) 146-159

Hart, G.C., Yao, T.P., (1977). "System identification in structural dynamics." Journal of Engineering Mechanics 103(6), 1089-1104

Hudson, S., Tufton, E., Cormie, D., Inglis, S., ( 2012). "Engineering Resilient Infrastructure". Civil Engineering, Proceedings of the Institution of Civil Engineers 165(CE6), 5-12.

Institution of Civil Engineers (2009). "The State of the Nation. Defending Critical Infrastructure.” ice.org.uk/Information-resources/Document-Library/State-ofthe-Nation--Defending-Critical-Infrastruc

Ivanovic, S., Trifunac, M.D., Novikova, E., (2000). “Ambient vibration tests of a sevenstorey RC building in Van Nuys, California, damaged by the 1994 Northridge Earthquake". Soil Dynamics and Earthquake Engineering 19(6) 391-411. 
Marashi E \& Davis JP (2006) "An argumentation-based method for managing complex issues in design of infrastructural systems." Reliability Engineering \& System Safety, 91(12).

Marjanishvili, S., Hinman, S.E., (2010). "A threat independent approach to evaluating the sustainability of our critical infrastructure." Paper 4.2 in: Aging Infrastructure: Issues, Research and Technology. Homeland Security Buildings and Infrastructure Protection Series BIPS 01.

Moyo, P., Brownjohn, J.M.W., (2002). “Application of Box-Jenkins models for assessing the impact of unusual events recorded by structural health monitoring systems.” International Journal of Structural Health Monitoring 1(2), 149-160.

Mufti, A.A, Bakht, B., Tadros, G., Horosko, A.T., Sparks, G., (2005). “Are civil structural engineers 'risk adverse'? Can civionics help?" Sensing Issues in Civil Structural Health Monitoring. Springer, ISBN 978-1-4020-3660-6.

Salawu OS, Williams C, (1995), "Assessment of bridges using forced-vibration testing." Journal of Structural Engineering. 121(2) 161-173.

Taleb, N.N., (2007). The Black Swan. Random House.

Waters, N., (2009). "Engine health management." Ingenia 39, 37-42.

Wenzel, H., (2009). "From structural health monitoring to risk based infrastructure management." Proceedings, Structural Health Monitoring of Intelligent Infrastructure, Zurich.

Yun, H., Nayeri, R., Tasbihgoo, F., Wabheh, M., Caffrey, J., Wolfe, R., Nigbor, R., Masri, S.F., Abdel-Ghaffar, A., Sheng, L-H., (2008). "Monitoring the collision of a cargo ship with the Vincent Thomas Bridge." Structural Control and Health Monitoring 15 183-206. 